\title{
Effect of fermented milk product containing lactotripeptides and plant sterol esters on haemodynamics in subjects with the metabolic syndrome - a randomised, double-blind, placebo-controlled study
}

\author{
Elina J. Hautaniemi ${ }^{1,2 *}$, Antti J. Tikkakoski ${ }^{1,3}$, Anna Tahvanainen ${ }^{1,4}$, Klaus Nordhausen ${ }^{5,6}$, \\ Mika Kähönen $^{1,3}$, Tiina Mattsson ${ }^{7}$, Satu Luhtala ${ }^{7}$, Anu M. Turpeinen ${ }^{7}$, Onni Niemelä ${ }^{1,8}$, \\ Heikki Vapaatalo9, Riitta Korpela9 and Ilkka H. Pörsti ${ }^{1,4}$ \\ ${ }^{1}$ School of Medicine, University of Tampere, Tampere, Finland \\ ${ }^{2}$ Nutrition Unit, Tampere University Hospital, Tampere, Finland \\ ${ }^{3}$ Department of Clinical Physiology, Tampere University Hospital, Tampere, Finland \\ ${ }^{4}$ Department of Internal Medicine, Tampere University Hospital, Tampere, Finland \\ ${ }^{5}$ School of Health Sciences, University of Tampere, Tampere, Finland \\ ${ }^{6}$ Department of Mathematics and Statistics, University of Turku, Turku, Finland \\ ${ }^{7}$ Valio Limited, Research and Development, Helsinki, Finland \\ ${ }^{8}$ Department of Laboratory Medicine and Medical Research Unit, Seinäjoki Central Hospital, Seinäjoki, Finland \\ ${ }^{9}$ Faculty of Medicine, Department of Pharmacology, University of Helsinki, Helsinki, Finland
}

(Submitted 26 November 2014 - Final revision received 4 May 2015 - Accepted 13 May 2015 - First published online 14 July 2015)

\section{Abstract}

We investigated the effects of fermented milk product containing isoleucine-proline-proline, valine-proline-proline and plant sterol esters (Pse) on plasma lipids, blood pressure (BP) and its determinants systemic vascular resistance and cardiac output. In a randomised, double-blind, placebo-controlled study, 104 subjects with the metabolic syndrome (MetS) were allocated to three groups in order to receive fermented milk product containing (1) $5 \mathrm{mg} / \mathrm{d}$ lactotripeptides (LTP) and $2 \mathrm{~g} / \mathrm{d}$ plant sterols; (2) $25 \mathrm{mg} / \mathrm{d}$ LTP and $2 \mathrm{~g} / \mathrm{d}$ plant sterols; (3) placebo for 12 weeks. Plasma lipids and home BP were monitored. Haemodynamics were examined in a laboratory using radial pulse wave analysis and whole-body impedance cardiography in the supine position and during orthostatic challenge. There were no differences between the effects of the two treatments and placebo on the measurements of BP at home or on BP, systemic vascular resistance index and cardiac index in the laboratory, neither in the supine nor in the upright position. The changes in plasma LDL-cholesterol concentration were $-0 \cdot 1(95 \% \mathrm{CI}-0 \cdot 3,0 \cdot 1$ and $-0 \cdot 3,0 \cdot 0) \mathrm{mmol} / \mathrm{l}$ in the 5 and $25 \mathrm{mg} / \mathrm{d} \mathrm{LTP}$ groups, respectively, and $+0 \cdot 1(95 \% \mathrm{CI}-0 \cdot 1,0 \cdot 3) \mathrm{mmol} / \mathrm{l}$ during placebo $(P=0.024)$. Both at baseline and at week 12, the increase in systemic vascular resistance during head-up tilt was lower in the $25 \mathrm{mg} / \mathrm{d}$ LTP group than in the $5 \mathrm{mg} / \mathrm{d}$ LTP group $(P<0 \cdot 01)$, showing persistent differences in cardiovascular regulation between these groups. In subjects with the MetS, intake of LTP and Pse in fermented milk product showed a lipid-lowering effect of borderline significance, while no antihypertensive effect was observed at home or in the laboratory.

Key words: Lactotripeptides: Blood pressure: Systemic vascular resistance index: Plant sterol esters: Cholesterol

Hypertension is a major risk factor for CVD, and it often clusters with other risk factors including central obesity, dyslipidaemia and insulin resistance. The metabolic syndrome (MetS) is a combination of these cardiometabolic risk factors, and it has been associated with an increased risk of type 2 diabetes and atherosclerotic $\mathrm{CVD}^{(1)}$. The prevalence of the MetS is about $20 \%$ among adult population ${ }^{(1)}$.
Lifestyle changes, such as reduction of salt and SFA intake, increase in low-fat dairy product, fruit and vegetable intake, weight reduction and increase in physical activity, play a key role in the prevention and treatment of hypertension and its related disorders ${ }^{(2)}$. The possible antihypertensive effect of dairy product intake has been linked to the intake of $\mathrm{Ca}, \mathrm{K}$ and $\mathrm{Mg}$, minerals that exist in rich amount in

Abbreviations: BP, blood pressure; Ile-Pro-Pro, isoleucine-proline-proline; LTP, lactotripeptides; LTP5 + Pse, 5 mg/d lactotripeptides and 2 g/d plant sterol esters; LTP25 + Pse, $25 \mathrm{mg} / \mathrm{d}$ lactotripeptides and $2 \mathrm{~g} / \mathrm{d}$ plant sterol esters; MetS, metabolic syndrome; Pse, plant sterol esters; SVRI, systemic vascular resistance index; Val-Pro-Pro, valine-proline-proline.

*Corresponding author: E. J. Hautaniemi, fax +3583364 1472, email elina.hautaniemi@uta.fi 
milk $^{(3)}$, and to bioactive peptides released from milk protein through gastrointestinal digestion, microbial fermentation or enzymatic hydrolysis ${ }^{(4)}$.

Recently, three meta-analyses have reported that intake of the milk casein-derived lactotripeptides (LTP) isoleucineproline-proline (Ile-Pro-Pro) and valine-proline-proline (Val- Pro-Pro) decreases systolic blood pressure (BP) by about $4-5 \mathrm{mmHg}$ and diastolic BP by about $2 \mathrm{mmHg}^{(5-7)}$. Another meta-analysis by Pripp ${ }^{(8)}$ has included clinical trials on both LTP and other peptides derived from food, and has found a lowering effect on systolic/diastolic BP of about $5 / 2 \mathrm{mmHg}$. One animal study has suggested that the antihypertensive mechanism of Ile-Pro-Pro and Val-Pro-Pro is competitive inhibition of the angiotensin-converting enzyme $(\mathrm{ACE})^{(9)}$. However, contradictory data also exist, as several clinical trials have reported that LTP are without significant influences on $\mathrm{BP}^{(10-12)}$.

The cholesterol-lowering effect of phytosterols (plant sterols and stanols) is well established, as these compounds inhibit the absorption of dietary and endogenous cholesterol and up-regulate intestinal cholesterol efflux transporters ${ }^{(13)}$. Daily intake of $2 \mathrm{~g}$ of plant sterols or stanols has been reported to reduce total and LDL-cholesterol levels by approximately $10 \%{ }^{(14)}$. The efficacy of plant sterols/stanols is affected by subjects' baseline LDL levels, food carrier, and frequency and timing of sterol intake ${ }^{(14)}$

Moreover, two long-term intervention studies have examined the effects of simultaneous intake of LTP and plant sterol esters (Pse) on cardiovascular risk factors in hypertensive and hypercholesterolaemic subjects ${ }^{(15,16)}$. In these studies, the intake of $4.2 \mathrm{mg}$ LTP with $2 \mathrm{~g}$ Pse in a low-fat spread had been reported to decrease systolic BP by $4-6 \mathrm{mmHg}$ and LDL-cholesterol concentrations by $0 \cdot 2-0.3 \mathrm{mmol} / \mathrm{l}$. However, the BP-lowering effect was not consistent in all measurements performed at home, in the office or during ambulatory 24 -h recordings ${ }^{(15,16)}$.

Since the evidence about the BP-lowering properties of LTP remains contradictory, we tested the hypothesis whether simultaneous intake of LTP and Pse in fermented milk product lowers BP in subjects with the MetS. For this purpose, two doses of Ile-Pro-Pro and Val-Pro-Pro $(5$ and $25 \mathrm{mg} / \mathrm{d}$ ) were studied, and since the concurrent reduction in plasma lipids can be anticipated to provide additional cardiovascular benefits, both products also contained $2 \mathrm{~g} / \mathrm{d}$ of Pse. For the first time, the long-term effects on haemodynamics were examined in a clinical physiology laboratory in a doubleblind, randomised, parallel-group set up.

\section{Methods \\ Ethical statement}

The present study was conducted according to the guidelines laid down in the Declaration of Helsinki, and all procedures involving human subjects were approved by the Ethics Committee of Tampere University Hospital (Study code R08012). Written informed consent was obtained from all subjects. The present study is a part of an ongoing investigation, in which haemodynamic measurements are non-invasively recorded (DYNAMIC-study; Clinical Trials registration number NCT01742702), and the recording protocol is also registered in the EU Clinical Trials Register (EudraCT number 2006-002065-39).

\section{Study subjects}

Altogether, 116 subjects aged 35-62 years with the MetS were recruited through announcements in a local newspaper. The inclusion criteria were waistline $\geq 94 \mathrm{~cm}$ for men and $\geq 80 \mathrm{~cm}$ for women, systolic $\mathrm{BP} \geq 140 \mathrm{mmHg}$ or diastolic $\mathrm{BP} \geq 85 \mathrm{mg}$, and at least one of the following: plasma TAG $\geq 1.7 \mathrm{mmol} / \mathrm{l}$; HDL-cholesterol concentration $<1.03 \mathrm{mmol} / 1$ in men and $<1.29 \mathrm{mmol} / 1$ in women; fasting glucose $\geq 5.6 \mathrm{mmol} / 1$. The exclusion criteria were use of antihypertensive or lipid-lowering medication, secondary hypertension, unstable coronary artery disease, diabetes, malignancy, milk allergy, smoking, alcohol abuse, pregnancy and lactation.

Of the total study subjects, one discontinued the study during the run-in, and three subjects on placebo and two on $25 \mathrm{mg}$ LTP $+2 \mathrm{~g}$ Pse discontinued the study during the intervention due to personal reasons; four subjects were excluded because they had failed to report the use of statin ( $n$ 1) or metformin ( $n$ 3) at study entry, and two subjects due to technical problems during haemodynamic recordings. Altogether, 104 subjects (sixty-three males and forty-one females) were included in the final analysis.

\section{Study design}

The present study was randomised, double-blind and placebo-controlled with a parallel design containing two intervention groups on different peptide concentrations and a control group. Separate randomisation lists were used for men and women. During a 4 -week run-in period, commercial fermented milk product without the test substances was given twice daily to familiarise the subjects with the trial procedure. After run-in, the subjects received fermented milk product containing (1) $5 \mathrm{mg} / \mathrm{d}$ LTP and $2 \mathrm{~g} / \mathrm{d}$ Pse (LTP $5+$ Pse); (2) $25 \mathrm{mg} / \mathrm{d}$ LTP $+2 \mathrm{~g} / \mathrm{d}$ Pse (LTP25 + Pse); (3) placebo without added LTP and Pse. The product dose was $125 \mathrm{ml}$ twice daily during the 12 -week intervention. The subjects were instructed to maintain their medication, lifestyle and dietary habits constant during the study period and to register the use of the test products to study diaries.

Medications, use of vitamins and other nutrient supplements, and lifestyle habits were reviewed by structured questionnaires. Routine laboratory tests were taken at screening. At weeks 0, 8 and 12, blood samples after approximately $12 \mathrm{~h}$ of fasting were collected, and the subjects were weighed. Laboratory measurements included full blood count, C-reactive protein, glucose, creatinine, uric acid, Ca, phosphate ( 0 and 12 weeks), plasma lipids, $\mathrm{Na}$ and $\mathrm{K}(0,8$ and 12 week). BP was measured at home twice a week during the intervention (see below), and haemodynamic measurements were recorded at weeks 0,8 and 12 . 


\section{Study products}

All the study products were produced by Valio Limited. The runin product was a non-fat fermented milk product, different from the test and placebo products, without bioactive LTP and Pse. During the intervention, the fermented milk products contained Ile-Pro-Pro and Val-Pro-Pro ( 5 or $25 \mathrm{mg} / \mathrm{d}$ ) and Pse ( $2 \mathrm{~g} / \mathrm{d})$. LTP were added to the test products in the form of peptide powder. The peptides were separated from Lactobacillus belveticus Lc 1936 fermented milk, concentrated using nanofiltration and dried to produce powder. Pse were prepared by esterification of free plant sterols with fatty acids obtained from vegetable oil (Cognis Corporation) and contained $\beta$-sitosterol max $80 \%$, campesterol max $40 \%$, stigmasterol max $30 \%$, $\beta$-sitostanol max $15 \%$ and campestanol max $5 \%$. Other sterols and stanols were present at $<5 \%$. Placebo was a fermented milk product without LTP and Pse. The daily $250 \mathrm{ml}$ dose of both test products contained $3 \mathrm{~g}$ fat, $10 \mathrm{~g}$ protein and $25 \mathrm{~g}$ carbohydrates, and that of placebo contained $1 \mathrm{~g}$ fat, $8 \mathrm{~g}$ protein and $32 \mathrm{~g}$ carbohydrates. The energy content of the products was similar. The daily contents of $\mathrm{Ca}, \mathrm{K}$ and $\mathrm{Mg}$ in the test products were 380, 660 and $41 \mathrm{mg}$, respectively, and 250, 375 and $28 \mathrm{mg}$ in placebo, respectively.

\section{Laboratory analyses}

Blood count was determined using ADVIA 120 or 2120 (Bayer Health Care), and other laboratory values were determined using Cobas Integra 700/800 (F. Hoffmann-LaRoche Limited). Total cholesterol, HDL and TAG levels were measured enzymatically, and LDL level was calculated using the Friedewald equation ${ }^{(17)}$. Plasma insulin was determined using electrochemiluminescence assay on Cobas e 411 analyser (Roche Diagnostics). Plasma renin activity was measured using GammaCoat Plasma Renin Activity assay (Diasorin). Aldosterone concentrations were analysed by active aldosterone RIA (Diagnostics Systems Laboratories, Beckman Coulter). Estimated creatinine-based glomerular filtration rate was calculated using the RULE formula ${ }^{(18)}$, as the plasma creatinine values were within the normal range.

\section{Blood pressure measurements in the office and at home, and body weight}

Brachial office BP was measured in duplicate using an automated sphygmomanometer (Omron M4; Omron Matsusaka Limited) after $5 \mathrm{~min}$ rest in the sitting position at screening and at the end of the intervention ${ }^{(2)}$. Height and waist and hip circumference were measured to the closest $0.5 \mathrm{~cm}$ at screening. Body weight with subject in light clothing was monitored using a digital scale at every visit. After hands-on instructions, home BP (Omron M4) was measured twice a week (one weekday and one weekend day) in the morning approximately $1 \mathrm{~h}$ after waking up.

\section{Pulse wave analysis and whole-body impedance cardiography}

Haemodynamic recordings using continuous radial pulse wave analysis (SpygmoCor PWMx; Atcor Medical) and whole-body impedance cardiography (CircMon ${ }^{\mathrm{R}}$; JR Medical Limited) were performed in a quiet, temperature-controlled laboratory as reported previously in detail ${ }^{(19,20)}$. The pulse wave analysis probes in the left arm were at the level of the heart throughout the measurements. For $5 \mathrm{~min}$, the subjects were resting supine on the tilt table, followed by $5 \mathrm{~min}$ of head-up tilt to $60^{\circ}$, and then the tilt table was returned to the horizontal position for 5 min. The electrode configuration ${ }^{(21-23)}$ and the good repeatability and reproducibility of the measurements has been reported $^{(19)}$. Caffeine-containing products, smoking, heavy meal for at least $4 \mathrm{~h}$ and alcohol for at least $24 \mathrm{~h}$ before the recording were to be avoided.

\section{Statistical analyses}

With a sample size of thirty-five per group, the present study had a $82 \%$ power for detecting a $7 \mathrm{mmHg}$ difference in systolic BP by using standard deviation 10, $\alpha$-level 0.05 and power analysis method for two-sample $t$ test $^{(24)}$. Statistical analyses were performed using SPSS for Windows 17.0 (SPSS, Inc.). Home and office BP were given as the mean of two measurements. For home BP, the values from the last week of each period were used. The changes in response to head-up tilt were calculated as mean differences between supine values for 3-5 min and head-up tilt values for 3-5 min, when the signal was most stable. The results are given as crude means with standard deviations or $95 \%$ CI, unless stated otherwise. The normal distribution of variables was checked with the Shapiro-Wilk test before further analyses. The equality of variances among the study groups was tested with Levene's test for homogeneity of variances. Baseline values between the groups were compared using univariate ANOVA, and changes between the groups with corresponding baseline value as a covariate. ANOVA for repeated measurements was used to test (1) interaction of time and group; (2) differences between groups; (3) differences over time in continuous variables. Post hoc comparisons were adjusted with the Bonferroni correction. Adjustment for age was performed when appropriate. To compare within-group haemodynamic response to tilt at 0 and 12 weeks, paired samples $t$ test was utilised. Non-continuous variables were tested using $\chi^{2}$ test. $P<0.05$ was considered statistically significant.

\section{Results}

\section{Study subjects and compliance}

At baseline, there were no significant differences in sex distribution, BMI, office BP, fasting plasma glucose and insulin, lipids, quantitative insulin sensitivity check index (QUICKI) ${ }^{(25)}$ and estimated glomerular filtration rate ${ }^{(18)}$ between the groups (Table 1). The average QUICKI index values were clearly within the insulin-resistant range ${ }^{(25)}$. The mean age was $4-5$ years higher in the LTP25 + Pse group than in the LTP5 + Pse and placebo groups. In addition, in females, the waist:height ratio $^{(26)}$ was higher in the LTP25 + Pse than in the placebo group (Table 1). Body weight and fasting plasma glucose, renin 
Table 1. Clinical and metabolic characteristics of the study subjects at baseline

(Mean values and standard deviations; $n$ 104)

\begin{tabular}{|c|c|c|c|c|c|c|c|}
\hline & \multicolumn{2}{|c|}{ LTP5 + Pse (n 36) } & \multicolumn{2}{|c|}{ LTP25 + Pse (n 35) } & \multicolumn{2}{|c|}{ Placebo ( $n$ 33) } & \multirow[b]{2}{*}{$P \neq($ ANOVA) } \\
\hline & Mean & SD & Mean & SD & Mean & SD & \\
\hline Age (years) & $49 \cdot 5$ & $6 \cdot 9$ & $54 \cdot 3^{\star \star} \dagger$ & $5 \cdot 9$ & $50 \cdot 2$ & $7 \cdot 2$ & 0.007 \\
\hline Male/female & \multicolumn{2}{|c|}{$21 / 15$} & \multicolumn{2}{|c|}{$22 / 13$} & \multicolumn{2}{|c|}{$20 / 13$} & $0.927 \S$ \\
\hline BMI $\left(\mathrm{kg} / \mathrm{m}^{2}\right)$ & 30.5 & 4.5 & 31.5 & 3.5 & $30 \cdot 0$ & 3.7 & 0.109 \\
\hline \multicolumn{8}{|l|}{ Waist:height ratio|| } \\
\hline Male & 0.60 & 0.06 & 0.61 & 0.04 & 0.59 & 0.05 & 0.322 \\
\hline Female & 0.59 & 0.06 & $0.64^{*}$ & 0.06 & 0.58 & 0.04 & 0.044 \\
\hline Office SBP (mmHg) & 159 & 12 & 168 & 20 & 162 & 15 & 0.229 \\
\hline Office DBP (mmHg) & 97 & 8 & 102 & 10 & 100 & 10 & 0.100 \\
\hline $\mathrm{Hb}(\mathrm{g} / \mathrm{l})$ & 149 & 12 & 146 & 12 & 149 & 14 & 0.985 \\
\hline \multicolumn{8}{|l|}{ Fasting plasma } \\
\hline Total cholesterol $(\mathrm{mmol} / \mathrm{l})$ & $5 \cdot 6$ & 1.0 & $5 \cdot 7$ & 0.6 & $5 \cdot 7$ & 0.8 & 0.903 \\
\hline HDL-cholesterol (mmol/l) & 1.32 & 0.39 & 1.42 & 0.34 & 1.34 & 0.31 & 0.944 \\
\hline LDL-cholesterol (mmol/l) & 3.5 & 0.8 & 3.5 & 0.7 & 3.5 & 0.7 & 0.875 \\
\hline $\mathrm{TAG}(\mathrm{mmol} / \mathrm{l})$ & 2.05 & 1.14 & 1.80 & 0.88 & 1.77 & 0.86 & 0.535 \\
\hline Insulin (mU/l) & 10 & 7 & 8 & 4 & 9 & 3 & 0.406 \\
\hline QUICKI indexף & 0.147 & 0.015 & 0.158 & 0.040 & 0.150 & 0.011 & 0.473 \\
\hline eGFR $\left(\mathrm{ml} / \mathrm{min}\right.$ per $\left.1.73 \mathrm{~m}^{2}\right)$ 㧊 & 113 & 14 & 106 & 12 & 111 & 14 & 0.713 \\
\hline
\end{tabular}

LTP5 + Pse, $5 \mathrm{mg} / \mathrm{d}$ lactotripeptides and $2 \mathrm{~g} / \mathrm{d}$ plant sterol esters; LTP25 + Pse, $25 \mathrm{mg} / \mathrm{d}$ lactotripeptides and $2 \mathrm{~g} / \mathrm{d}$ plant sterol esters; SBP, systolic blood pressure; DBP, diastolic blood pressure; eGFR, estimated creatinine-based glomerular filtration rate.

Mean value was significantly different from that of the placebo group: * $P=0.048,{ }^{* \star} P=0.038$.

† Mean value was significantly different from that of the LTP5 + Pse group $(P=0.009)$.

$\ddagger$ Age as covariate.

$\S \chi^{2}$ test.

॥Waist:height ratio(26)

II Insulin-sensitivity QUICKI index ${ }^{(25)}$

‡†RULE formula ${ }^{(18)}$

activity, aldosterone, $\mathrm{K}, \mathrm{Na}$ and $\mathrm{K}: \mathrm{Na}$ ratio remained virtually unchanged during the study period (Table 2).

The subjects presented with the following diagnoses; however, all of the clinical conditions listed below were stable and well controlled or in remission: allergy ( $n$ 21); arthrosis ( $n 2)$; asthma ( $n$ 1); benign prostate hyperplasia ( $n 1)$; depression ( $n$ 11); epilepsy ( $n$ 1); fibromyalgia ( $n$ 1); gastro-oesophageal reflux ( $n$ 1); Gilbert's syndrome ( $n$ 2); glaucoma $(n 1)$; gout ( $n$ 4); hypothyroidism ( $n$ 8); paroxysmal atrial fibrillation ( $n$ 1); restless legs ( $n 1)$; rheumatoid arthritis $(n 1)$; systemic lupus erythematosus $(n 1)$. The medications used by the subjects are tabulated in online Supplementary Digital Content 1.

The mean duration of the intervention period was 84 (SD 4), 83 (SD 4) and 82 (SD 5) d in the LTP5 + Pse, LTP25 + Pse and placebo groups, respectively. Compliance was excellent, as only one subject (LTP5 + Pse group) consumed $<80 \%$ of the test products. Although the subjects were instructed to maintain their normal lifestyle and dietary habits, some subjects reported minor modifications that are shown in online Supplementary Digital Content 2.

\section{Home blood pressure measurements}

Mean values of home BP measurements at weeks 0, 8 and 12 are presented in Table 3. Neither of the treatments influenced $\mathrm{BP}$, as there were no significant group $\times$ time interactions in systolic and diastolic BP during the study period. Home diastolic BP was lower in the LTP5 + Pse group than in the LTP25 + Pse group $(P=0.009)$; however, neither of these groups differed from placebo. Home systolic and diastolic
BP were slightly reduced in all groups from baseline to week 12 (Table 3).

\section{Haemodynamic measurements in the laboratory}

The haemodynamic baseline data, captured during the 15-min recording protocol, are shown in Fig. 1. ANOVA for repeated measurements (age as covariate) showed a significant group $\times$ time interaction in radial systolic $(P=0.009)$ and diastolic $(P=0.004) \mathrm{BP}$ and systemic vascular resistance index (SVRI) $(P=0.001)$, but not in cardiac index $(P=0 \cdot 186)$, during the 15-min protocol at baseline. Thus, functional haemodynamic regulation was not corresponding in all study groups, and the clearest difference was that the LTP5 + Pse group showed lower supine, but not upright, DBP and SVRI than the placebo group.

Changes in the haemodynamic variables during the 15 -min recording protocol from week 0 to week 12 are presented in Fig. 2. ANOVA for repeated measurements (with age as covariate) showed no significant group $\times$ time interactions, or differences between the groups or within the groups, in the changes in radial systolic and diastolic BP, SVRI or cardiac index. Similarly, no BP-lowering effects of LTP + Pse diets were observed at week 8 (data not shown).

The cardiovascular response to head-up tilt at baseline and after 12 weeks of intervention is shown in Fig. 3. Within groups, there were no significant differences in the systolic BP or SVRI response to head-up tilt at weeks 0 and 12; however, in the LTP5 + Pse and placebo group, the cardiac index response to head-up tilt showed a greater reduction at week 
Table 2. Body weight and plasma glucose, electrolytes, renin and aldosterone during the study period (Mean values and standard deviations)

\begin{tabular}{|c|c|c|c|c|c|c|c|}
\hline & \multicolumn{2}{|c|}{ LTP5 + Pse (n 36) } & \multicolumn{2}{|c|}{ LTP25 + Pse (n 35) } & \multicolumn{2}{|c|}{ Placebo ( $n 33)$} & \multirow[b]{2}{*}{$P^{\star}$ (ANOVA) } \\
\hline & Mean & SD & Mean & SD & Mean & SD & \\
\hline \multicolumn{8}{|l|}{ Weight } \\
\hline Week 0 & $92 \cdot 1$ & $17 \cdot 6$ & $93 \cdot 7$ & $12 \cdot 3$ & 89.8 & $14 \cdot 2$ & 0.070 \\
\hline Week 12 & $92 \cdot 0$ & $17 \cdot 7$ & 94.1 & $12 \cdot 9$ & $90 \cdot 0$ & $14 \cdot 1$ & 0.051 \\
\hline Weight change in 12 weeks & -0.1 & $1 \cdot 7$ & 0.5 & $2 \cdot 1$ & $0 \cdot 2$ & 1.8 & 0.300 \\
\hline \multicolumn{8}{|l|}{ Plasma fasting } \\
\hline \multicolumn{8}{|l|}{ Glucose (mmol/l) } \\
\hline Week 0 & $5 \cdot 8$ & 0.7 & 5.9 & 0.6 & $5 \cdot 7$ & 0.5 & 0.528 \\
\hline Week 12 & $5 \cdot 8$ & 0.7 & $5 \cdot 9$ & 0.6 & $5 \cdot 7$ & 0.5 & 0.458 \\
\hline \multicolumn{8}{|l|}{ Renin activity $(\mu \mathrm{g} / / \mathrm{per} \mathrm{h})$} \\
\hline Week 0 & 0.58 & 0.48 & 0.69 & 0.68 & 0.90 & 0.74 & 0.111 \\
\hline Week 12 & 0.80 & 0.89 & 0.79 & 0.84 & 1.03 & 0.91 & 0.470 \\
\hline \multicolumn{8}{|l|}{ Aldosterone $(\mathrm{pmol} / \mathrm{l})$} \\
\hline Week 0 & 450 & 206 & 483 & 223 & 499 & 192 & 0.532 \\
\hline Week 12 & 486 & 275 & 501 & 254 & 510 & 214 & 0.745 \\
\hline \multicolumn{8}{|l|}{$\mathrm{K}(\mathrm{mmol} / \mathrm{l})$} \\
\hline Week 0 & $4 \cdot 0$ & 0.3 & $4 \cdot 1$ & 0.2 & $4 \cdot 0$ & 0.3 & 0.748 \\
\hline Week 12 & 3.9 & 0.3 & 3.9 & 0.2 & 3.9 & 0.3 & 0.396 \\
\hline \multicolumn{8}{|l|}{$\mathrm{Na}(\mathrm{mmol} / \mathrm{l})$} \\
\hline Week 0 & 140 & 2 & 140 & 2 & 140 & 2 & 0.961 \\
\hline Week 12 & 139 & 2 & 139 & 2 & 140 & 2 & 0.375 \\
\hline \multicolumn{8}{|l|}{$\mathrm{K}: \mathrm{Na}$ ratio $(\%)$} \\
\hline Week 0 & 2.9 & 0.2 & $2 \cdot 9$ & 0.2 & $2 \cdot 9$ & 0.2 & 0.766 \\
\hline Week 12 & $2 \cdot 8$ & 0.2 & $2 \cdot 8$ & 0.1 & $2 \cdot 8$ & 0.2 & 0.948 \\
\hline
\end{tabular}

LTP5 + Pse, 5 mg/d lactotripeptides and $2 \mathrm{~g} / \mathrm{d}$ plant sterol esters; LTP25 + Pse, $25 \mathrm{mg} / \mathrm{d}$ lactotripeptides and $2 \mathrm{~g} / \mathrm{d}$ plant sterol esters.

${ }^{*}$ Age as covariate.

12 than at baseline $(P=0.008$ and $P=0.036$, respectively). In addition, the diastolic BP response to head-up tilt decreased in the LTP5 + Pse group $(P=0 \cdot 046)$. The increase in SVRI during head-up tilt was lower in the LTP25 + Pse group than in the LTP5 + Pse group both at baseline and at week $12(P<0.01)$, showing consistent functional differences in haemodynamics between these groups.

\section{Plasma lipids and lipoproteins}

The changes in plasma lipid concentrations from baseline to week 12 are presented in Table 4. There was a numerical but not statistically significant tendency towards lower plasma LDL-cholesterol concentration after the intervention in the test groups $(P=0.066)$. When the two test groups with

Table 3. Home systolic (SBP) and diastolic blood pressure (DBP) during the intervention

(Mean values, standard deviations and $95 \%$ confidence intervals)

\begin{tabular}{|c|c|c|c|c|c|c|c|c|c|c|}
\hline & \multicolumn{2}{|c|}{$\begin{array}{l}\text { LTP5 + } \\
\text { Pse }(n 36)\end{array}$} & \multicolumn{2}{|c|}{$\begin{array}{l}\text { LTP25 + } \\
\text { Pse (n 35) }\end{array}$} & \multicolumn{2}{|c|}{$\begin{array}{l}\text { Placebo } \\
(n 32)\end{array}$} & \multicolumn{3}{|c|}{$P \dagger$ (ANOVA for repeated measures) } & \multirow[b]{2}{*}{$\begin{array}{c}P \ddagger \\
\text { (ANOVA) }\end{array}$} \\
\hline & Mean & SD & Mean & SD & Mean & SD & $\begin{array}{c}\text { Group } \times \text { time } \\
\text { interaction }\end{array}$ & $\begin{array}{l}\text { Between-group } \\
\text { difference }\end{array}$ & $\begin{array}{l}\text { Within-group } \\
\text { difference }\end{array}$ & \\
\hline \multicolumn{11}{|l|}{$\mathrm{SBP}(\mathrm{mmHg})$} \\
\hline 0 week & 139 & 11 & 147 & 17 & 139 & 14 & & & & \\
\hline 8 week & 137 & 13 & 144 & 17 & 138 & 14 & & & & \\
\hline 12 week & 138 & 13 & 145 & 17 & 137 & 15 & 0.746 & 0.055 & $0 \cdot 170$ & \\
\hline SBP change in 12 weeks $(\mathrm{mmHg}) \S$ & & & & & & & & & & 0.274 \\
\hline Mean & \multirow{2}{*}{\multicolumn{2}{|c|}{$\begin{array}{c}-1 \cdot 4 \\
-3 \cdot 9,1 \cdot 2\end{array}$}} & \multirow{2}{*}{\multicolumn{2}{|c|}{$\begin{array}{c}-1 \cdot 1 \\
-4 \cdot 7,2 \cdot 5\end{array}$}} & \multicolumn{2}{|c|}{$-2 \cdot 4$} & & & & \\
\hline $95 \% \mathrm{Cl}$ & & & & & $-5 \cdot 3$ & & & & & \\
\hline \multicolumn{11}{|l|}{$\mathrm{DBP}(\mathrm{mmHg})$} \\
\hline 0 week & 85 & 7 & 91 & 10 & 87 & 9 & \multirow{4}{*}{0.726} & \multirow{4}{*}{$0.011^{*}$} & \multirow{4}{*}{0.299} & \\
\hline 8 week & 84 & 8 & 89 & 9 & 85 & 8 & & & & \\
\hline 12 week & 84 & 8 & \multirow{2}{*}{\multicolumn{2}{|c|}{89}} & 86 & 9 & & & & \\
\hline \multicolumn{3}{|l|}{ DBP change in 12 weeks $(\mathrm{mmHg}) \S$} & & & & & & & & 0.256 \\
\hline Mean & \multirow{2}{*}{\multicolumn{2}{|c|}{$\begin{array}{c}-1 \cdot 3 \\
-3 \cdot 0,0.4\end{array}$}} & \multirow{2}{*}{\multicolumn{2}{|c|}{$\begin{array}{c}-1 \cdot 0 \\
-3 \cdot 1,1 \cdot 1\end{array}$}} & \multirow{2}{*}{\multicolumn{2}{|c|}{$\begin{array}{c}-1 \cdot 3 \\
-3 \cdot 1,0.4\end{array}$}} & & & & \\
\hline $95 \% \mathrm{Cl}$ & & & & & & & & & & \\
\hline
\end{tabular}

LTP5 + Pse, 5 mg/d lactotripeptides and $2 \mathrm{~g} / \mathrm{d}$ plant sterol esters; LTP25 + Pse, $25 \mathrm{mg} / \mathrm{d}$ lactotripeptides and $2 \mathrm{~g} / \mathrm{d}$ plant sterol esters.

*The LTP25 + Pse group differed significantly from LTP5 + Pse group $(P=0.009)$ in post hoc comparisons (Bonferroni corrections applied).

† Age as covariate.

$\ddagger$ Age and baseline measure as covariates.

$\S$ SBP and DBP change in 12 weeks is expressed as means and 95 percent confidence intervals. 

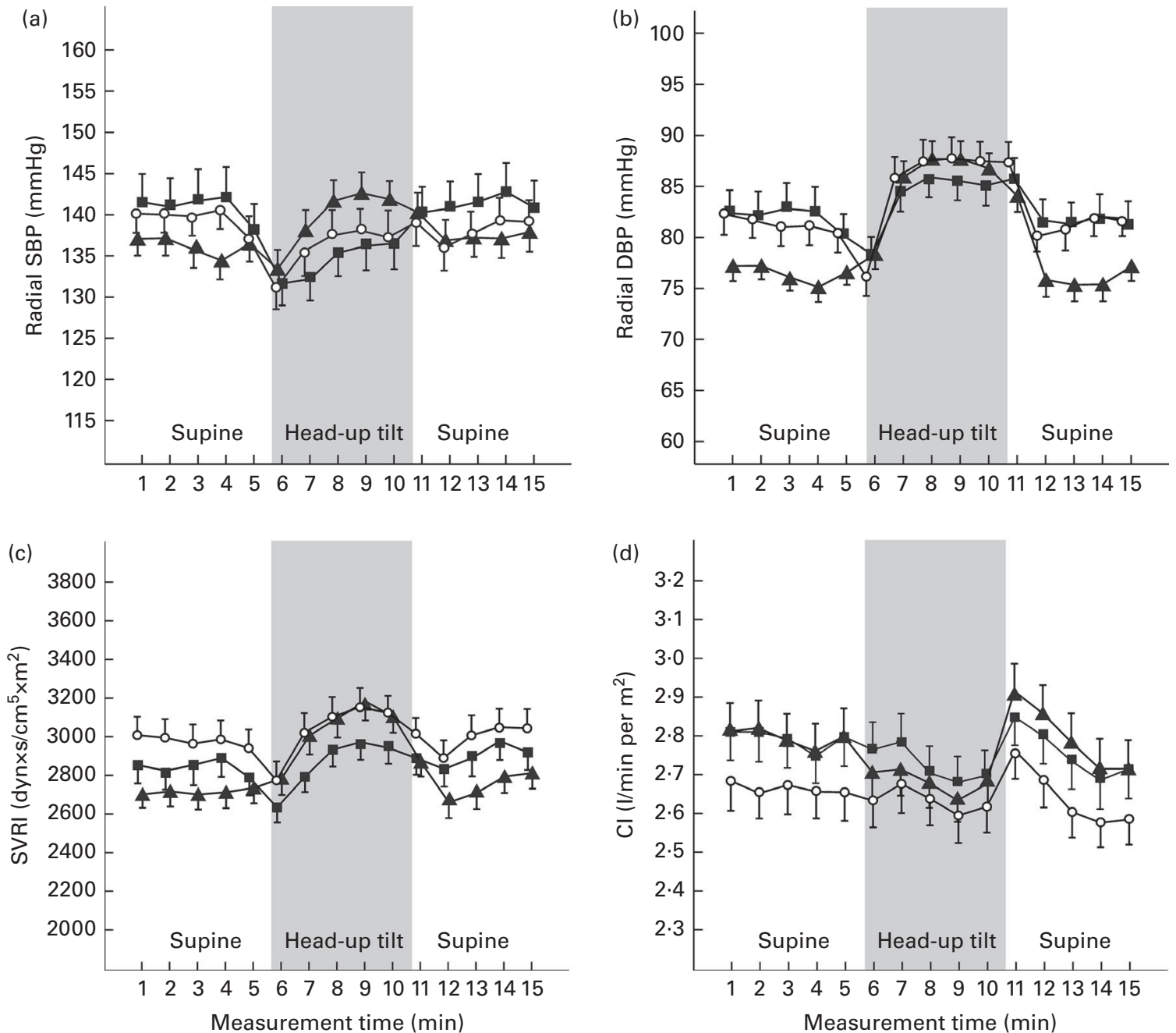

Fig. 1. Radial systolic blood pressure (a), radial diastolic blood pressure (b), systemic vascular resistance index (SVRI) (c) and cardiac index (CI) (d) during haemodynamic recordings performed at baseline. All subjects underwent the 15-min recordings during which the 5 -min head-up tilt was performed between 5 and $10 \mathrm{~min}$. Values are means, with their standard errors represented by vertical bars. (a) $P=0.009$ (group $\times$ time interaction), (b) $P=0.004$ (group $\times$ time interaction) and (c) $P=0.001$ (group $\times$ time interaction). O, Placebo; $\mathbf{\Lambda}$, LTP5 + Pse ( $5 \mathrm{mg} / \mathrm{d}$ lactotripeptides and $2 \mathrm{~g} / \mathrm{d}$ plant sterol esters); $\mathbf{\square}$, LTP25 + Pse (25 mg/d lactotripeptides and $2 \mathrm{~g} / \mathrm{d}$ plant sterol esters).

similar daily doses of Pse were analysed together as one group, the test treatment decreased LDL-cholesterol concentration compared with placebo $(P=0.024)$. Plasma total cholesterol, HDL-cholesterol and TAG concentrations were virtually unchanged in all study groups.

\section{Discussion}

At present, the evidence about the putative beneficial effect of LTP on BP remains contradictory ${ }^{(7,10-12)}$. Therefore, we conducted for the first time a clinical trial utilising detailed haemodynamic measurements to examine the possible BP-lowering efficacy of two doses of LTP ( $5 v .25 \mathrm{mg}$ daily) in a long-term, 12-week intervention. Since simultaneous reduction in plasma lipids can be anticipated to provide additional cardiovascular benefits, both of the LTP-products were fortified with Pse (daily dose $2 \mathrm{~g}$ ). However, the present results showed that intake of Ile-Pro-Pro and Val-Pro-Pro with Pse in fermented milk product was without significant antihypertensive effect; however, a borderline lipid-lowering effect was observed in 104 subjects with the MetS. Of note, the results on $\mathrm{BP}$ were consistent in measurements performed both at home and in the laboratory. The study also uncovered a significant haemodynamic difference in the SVRI response to head-up tilt between the LTP5 + Pse and LTP25 + Pse groups both at baseline and after 12 weeks of intervention. Thus, these two groups showed persistent functional cardiovascular differences in the supine to upright regulation of peripheral vascular resistance.

Previously, four meta-analyses including Asian and Caucasian subjects in 12-19 placebo-controlled trials, with interventions lasting from 4 to 21 weeks, and daily peptide doses ranging from 2 to $52.5 \mathrm{mg}$, have reported that products containing bioactive peptides may reduce BP by about $4-5 / 2$ (systolic/diastolic) $\mathrm{mmHg}^{(5-8)}$. Based on these previous studies, our 12-week intervention with doses of 5 and $25 \mathrm{mg}$ of LTP should have been sufficient for detecting a lowering effect on BP, if present. Of note, LTP have been suggested 

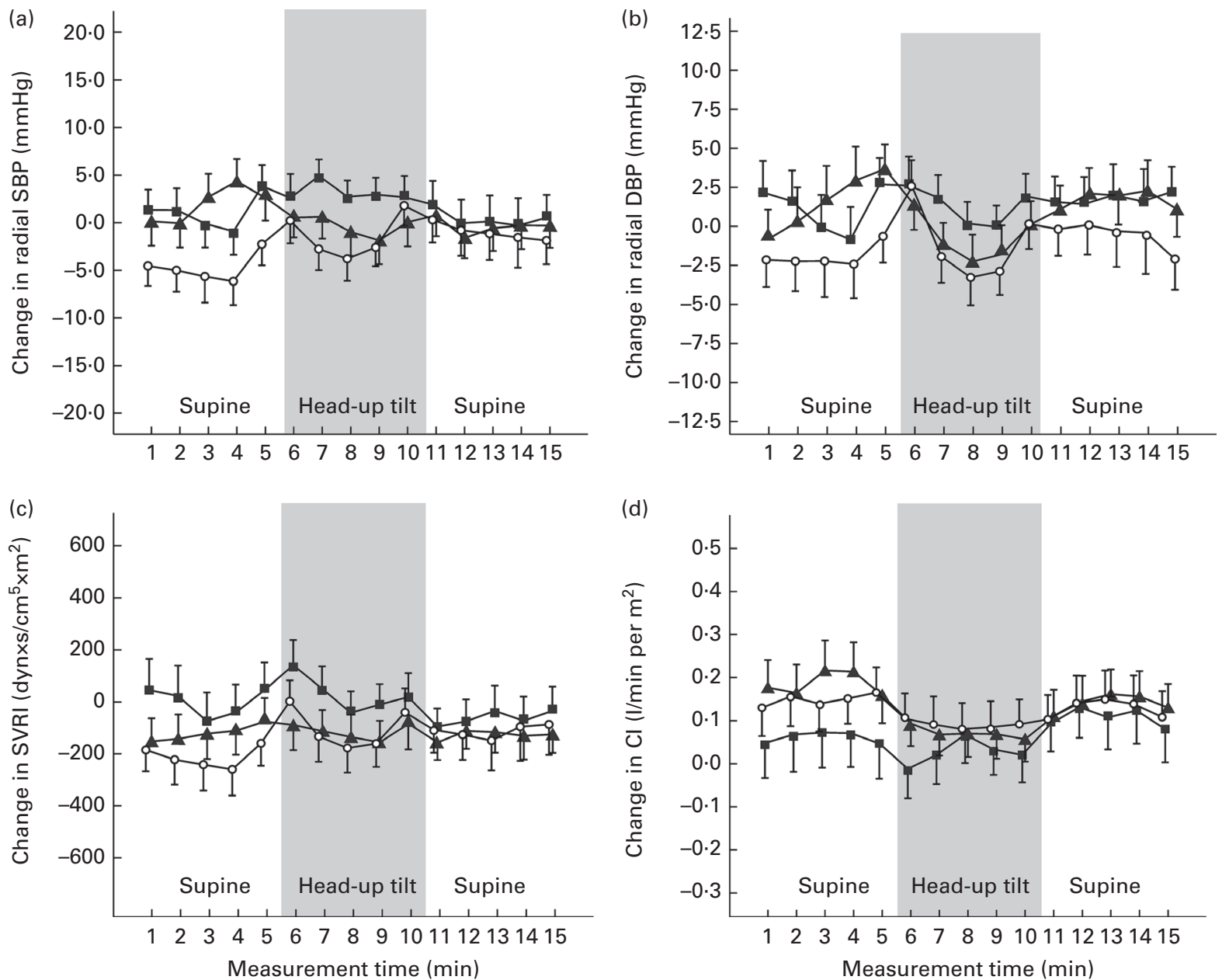

Fig. 2. Changes in radial systolic blood pressure (a), radial diastolic blood pressure (b), systemic vascular resistance index (SVRI) (c) and cardiac index (CI) (d) during the 15-min recording protocol as calculated from the first recording (at 0 weeks) to the third recording (after 12 weeks of intervention). The 5 -min head-up tilt was performed between 5 and $10 \mathrm{~min}$. Values are means, with their standard errors represented by vertical bars. O, Placebo; $\mathbf{\Lambda}$, LTP5 + Pse (5 mg/d lactotripeptides and $2 \mathrm{~g} / \mathrm{d}$ plant sterol esters); $\mathbf{\square}$, LTP25 + Pse ( $25 \mathrm{mg} / \mathrm{d}$ lactotripeptides and $2 \mathrm{~g} / \mathrm{d}$ plant sterol esters).

to show more pronounced BP-lowering effect in hypertensive subjects than in pre-hypertensive subjects $^{(7)}$. The present study population had a clearly elevated BP with a mean office BP of 163/100 mmHg at screening, and a mean home $\mathrm{BP}$ of $142 / 88 \mathrm{mmHg}$ in the beginning of the intervention.

Corresponding to the present results, Dutch intervention studies have shown no significant decreases in BP after intake of $4 \cdot 6-14 \mathrm{mg} / \mathrm{d}$ of Ile-Pro-Pro and Val-Pro-Pro for $4-8$ weeks $^{(10-12)}$. Furthermore, the BP-lowering effect of LTP may be influenced by ethnic factors. In the meta-analysis by Cicero et al. ${ }^{(5)}$, the effect of LTP is more pronounced in Asian subjects (systolic BP $-6.93 \mathrm{mmHg}$; diastolic $\mathrm{BP}-3.98 \mathrm{mmHg}$ ) than in European subjects (systolic $\mathrm{BP}-1.17 \mathrm{mmHg}$; diastolic $\mathrm{BP}-0.52)$, and is not related to age, baseline BP, dose of LTP or length of the treatment. One possibility is that differences in background diet may explain the variable responses to intake of LTP.

Results from experimental studies have suggested that LTP may have competitive ACE inhibiting activity ${ }^{(27)}$; however, this has not been confirmed in human subjects ${ }^{(28)}$. ACE inhibitor drugs that are used in the treatment of CVD have been reported to increase plasma renin activity, reduce plasma aldosterone concentration ${ }^{(29-31)}$ and elevate plasma $\mathrm{K}$ concentration $^{(32,33)}$. During the present study, there were no significant differences in plasma renin activity, plasma aldosterone and $\mathrm{K}$ concentrations, and plasma $\mathrm{K}: \mathrm{Na}$ ratio between the groups. These findings, together with the absence of changes in BP, indicate that the possible ACE inhibiting activity of the study products in vivo was not sufficiently strong to elicit detectable changes in the aforementioned variables.

Also, other modes of antihypertensive action for LTP, such as inhibition of the sympathetic nervous system and an effect on cardiac output, have been suggested ${ }^{(28,34)}$. Intake of Val-Pro-Pro and Ile-Pro-Pro slightly improved variables of cardiac flow (stroke volume and stroke index) and contractility (acceleration index and velocity index), but was without effect on variables of fluid dynamics or vascular resistance in subjects with high-normal BP or mild hypertension ${ }^{(34)}$. The present study showed no effect of LTP on systemic vascular resistance and cardiac index, which is in agreement with the results reported by Cicero et $a l .^{(34)}$. One previous study 
(a)

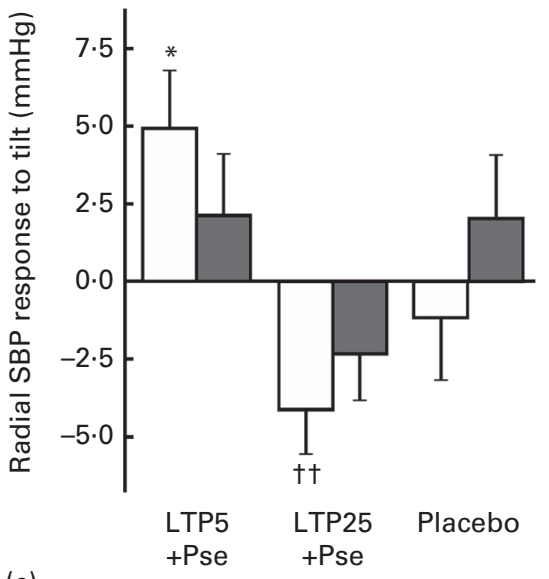

(c)

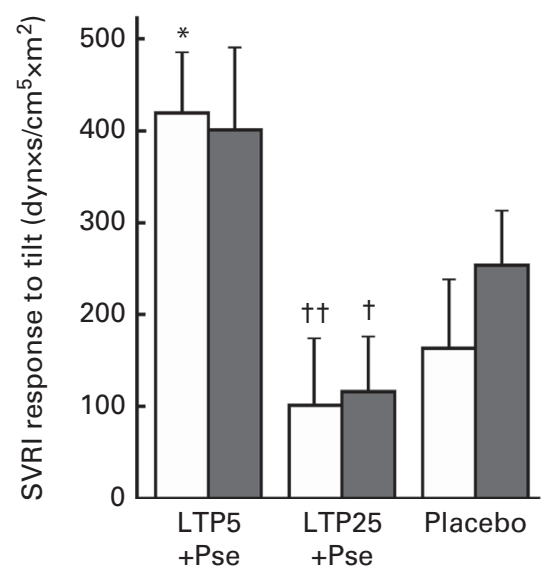

(b)

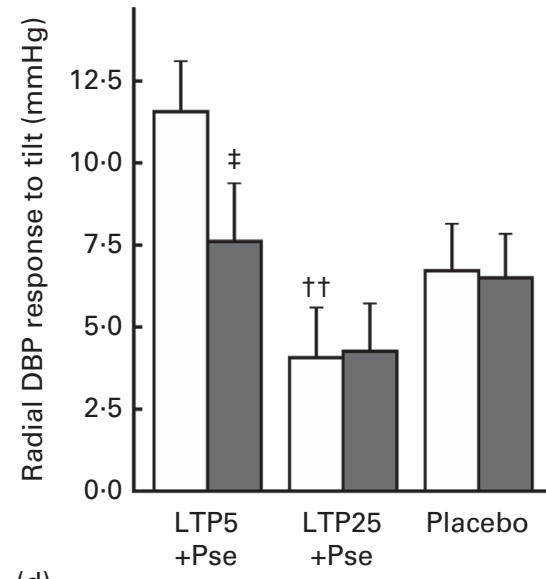

(d)

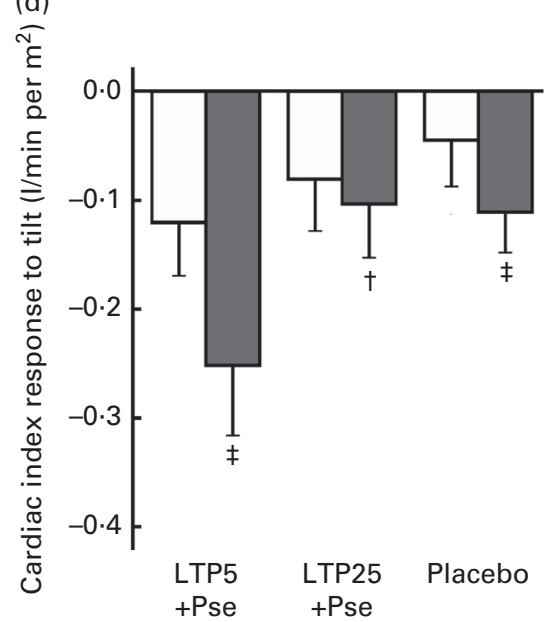

Fig. 3. Haemodynamic responses in the $5 \mathrm{mg} / \mathrm{d}$ lactotripeptides and $2 \mathrm{~g} / \mathrm{d}$ plant sterol esters (LTP $5+$ Pse), $25 \mathrm{mg} / \mathrm{d}$ lactotripeptides and $2 \mathrm{~g} / \mathrm{d}$ plant sterol esters (LTP25 + Pse) and placebo groups to upright posture at baseline ( $\square$ ) and after 12 weeks of intervention ( $\square$ ): radial systolic blood pressure (BP) (a), radial diastolic BP (b), systemic vascular resistance index (SVRI) (c) and cardiac index (d). Values are means, with their standard errors represented by vertical bars. Within groups, the haemodynamic responses at weeks 0 and 12 did not differ, apart from the accentuated cardiac index decline in the LTP5 + Pse and placebo groups at week $12(P=0.008$ and $P=0.036$, respectively), and the diastolic BP decline in the LTP5 + Pse group $(P=0.046)$. Paired-samples $t$ test applied in within-group comparisons, ANCOVA with age as covariate applied in between-group comparisons, with Bonferroni corrections in post hoc comparisons. ${ }^{*}$ Mean value was significantly different from that of the placebo group $(P<0.05)$. Mean value was significantly different from that of the LTP5 + Pse group: $† P<0.05, \dagger † P<0.01$. Mean value was significantly different from that at baseline for the same group: $\ddagger P<0.05$.

utilising a tilt table test has suggested that LTP intake may have a mild lowering effect on sympathetic activity, since plasma noradrenaline response to head-up tilt was reduced after 8 weeks of intervention, although no significant changes were seen in BP and heart rate ${ }^{(28)}$. In the present study, LTP treatment was without influence on radial BP either in supine position or during head-up tilt

In the present investigation, a simultaneous intake of LTP and Pse was used. In experimental studies, combined treatment with LTP and Pse had been found to attenuate the elevation of BP in spontaneously hypertensive rats ${ }^{(35)}$. However, the antihypertensive effect of combined LTP + Pse intake is less marked than the effect of LTP treatment alone $^{(35)}$, while Pse treatment alone did not affect $\mathrm{BP}^{(36)}$. Further, plant sterols have even been reported to increase BP in salt-loaded stroke-prone spontaneously hypertensive rats ${ }^{(37)}$. Based on these experimental results, it can be speculated whether the simultaneous administration of Pse attenuated the possible BP-lowering effect of LTP in the present study, and whether an even higher dose of LTP would have resulted in the lowering of BP. Nevertheless, in previous human studies, the simultaneous intake of LTP and Pse for 10 weeks had been shown to decrease systolic BP at home measurements, but not in the office or during 24-h ambulatory recordings ${ }^{(15,16)}$. In addition, a recent study has suggested an acute BP-lowering effect $8 \mathrm{~h}$ post-dose of fermented milk product containing $25 \mathrm{mg}$ LTP and $2 \mathrm{~g}$ Pse in subjects with mild hypertension ${ }^{(38)}$.

The present cholesterol-lowering effect of $2 \mathrm{~g}$ daily Pse intake remained modest when compared with a previous meta-analysis reporting a mean reduction of $0.31 \mathrm{mmol} / 1$ in plasma LDL-cholesterol concentration ${ }^{(14)}$. Earlier, the efficacy of plant stanols and sterols has been studied in different food matrices including low-fat milk products ${ }^{(14)}$, and the beneficial effects have been confirmed in both normocholesterolaemic and hypercholesterolaemic subjects ${ }^{(39)}$, as well as 
Table 4. Changes in plasma lipid concentrations during the study

(Mean values and $95 \%$ confidence intervals; $n$ 104)

\begin{tabular}{|c|c|c|c|c|c|c|c|}
\hline & \multicolumn{2}{|c|}{ LTP5 + Pse (n 36) } & \multicolumn{2}{|c|}{ LTP25 + Pse $(n$ 35) } & \multicolumn{2}{|c|}{ Placebo (n 33) } & \multirow[b]{2}{*}{$P^{\star}$ (ANOVA } \\
\hline & Mean & $95 \% \mathrm{Cl}$ & Mean & $95 \% \mathrm{Cl}$ & Mean & $95 \% \mathrm{Cl}$ & \\
\hline Total cholesterol $(\mathrm{mmol} / \mathrm{l})$ & -0.0 & $-0.3,0.2$ & -0.1 & $-0.3,0.1$ & $+0 \cdot 1$ & $-0.1,0.2$ & 0.465 \\
\hline LDL-cholesterol $(\mathrm{mmol} / \mathrm{l})$ & -0.1 & $-0.3,0.1$ & -0.1 & $-0.3,0.0$ & +0.1 & $-0.1,0.3$ & 0.066 \\
\hline HDL-cholesterol (mmol/li) & -0.06 & $-0.12,-0.00$ & -0.05 & $-0.12,0.01$ & -0.08 & $-0.15,-0.02$ & 0.716 \\
\hline TAG $(\mathrm{mmol} / \mathrm{l})$ & +0.02 & $-0.32,0.36$ & +0.10 & $-0.10,0.29$ & +0.11 & $-0.20,0.42$ & 0.742 \\
\hline
\end{tabular}

LTP5 + Pse, $5 \mathrm{mg} / \mathrm{d}$ lactotripeptides and $2 \mathrm{~g} / \mathrm{d}$ plant sterol esters; LTP25 + Pse, $25 \mathrm{mg} / \mathrm{d}$ lactotripeptides and $2 \mathrm{~g} / \mathrm{d}$ plant sterol esters.

${ }^{*}$ Age and baseline value as covariates.

in type 2 diabetic patients ${ }^{(40)}$. However, the efficacy of phytosterols in subjects with the MetS is contradictory, since negative results have been reported after intake of Pse-enriched milk, breakfast cereal and margarine ${ }^{(41,42)}$, while consumption of plant stanol ester yogurt drink has been shown to lower non-HDL-cholesterol in the MetS subjects ${ }^{(43)}$. In particular, reduced intestinal cholesterol absorption observed in the MetS subjects may interfere with the mechanism of action and efficacy of the plant sterols ${ }^{(41)}$. It should also be noted that seasonal variation of blood lipid levels in hypercholesterolaemic subjects, with a characteristic peak of total and LDL-cholesterol in fall/winter and trough in spring/ summer ${ }^{(44)}$ may have attenuated the cholesterol-lowering effect of the present study, half of which was conducted in fall. We observed a slight numeric increase in the mean values of total and LDL-cholesterol of the placebo group.

In addition to hypertension and dyslipidaemia, central obesity and insulin resistance have been associated with the MetS ${ }^{(1)}$. During the present intervention, BP, body weight and plasma glucose remained unaltered in all study groups. We did not investigate the change in plasma insulin at the end of the study. However, the absence of alterations in the above cardiometabolic risk factors suggests that insulin sensitivity did not significantly change in the groups during the study.

The particular strength of the present study is the randomised, double-blind, placebo-controlled design. In addition to home BP measurements, we utilised detailed cardiovascular reactivity test for determining haemodynamic information in both supine position and during orthostatic challenge. Furthermore, we used two doses ( 5 and $25 \mathrm{mg}$ ) of LTP and 12-week intervention. Compliance was excellent, and according to the unchanged body weight, the subjects were able to maintain their habitual lifestyle and dietary pattern during the intervention. Characteristically of studies examining the antihypertensive influences of various treatments, BP and SVRI were numerically lower after the 12-week follow-up also in the placebo group ${ }^{(45)}$.

The present study has some limitations. There were differences between the groups in the demographic characteristics at baseline, in spite of the randomisation protocol. Age was higher in the LTP25 + Pse group than in the LTP5 + Pse and placebo groups, and in female subjects, waist:height ratio was higher in the LTP25 + Pse group than in the placebo group. In addition, the results showed persistent functional differences in upright haemodynamics between the groups, since the increase in SVRI during orthostatic challenge remained lower in the LTP25 + Pse group than in the LTP5 + Pse group throughout the study. A cross-over protocol, instead of the present parallel design, would have reduced possible confounding resulting from the divergent cardiovascular regulation in the study groups. However, the differences in the control of peripheral vascular resistance during head-up tilt were difficult to anticipate, as there is very little previous information about dietary influences on upright cardiovascular regulation. As the present parallel study included two intervention groups and a control group during a relatively long-term period (12 weeks), a corresponding cross-over design with each subject receiving all treatments would have been more strenuous to carry out (36 weeks altogether), and this might also have reduced compliance. Finally, consumption of the study products was monitored by the use of study diaries, and compliance was calculated from the registrations of the study subjects. In order to really ensure the accurate intake of the study products, an intervention with a laborious controlled feeding protocol should have been used ${ }^{(46)}$.

In conclusion, the present study showed no antihypertensive effect of LTP and Pse intake in fermented milk product at home or in the laboratory, but a mild lipid-lowering effect in subjects with the MetS.

\section{Supplementary material}

To view supplementary material for this article, please visit http://dx.doi.org/10.1017/S0007114515002032

\section{Acknowledgements}

The authors are grateful to Reeta Kulmala, Research Nurse, and Paula Erkkilä, Research Nurse, for invaluable assistance.

The present study was supported by Valio Limited, Helsinki, Finland, and the Finnish Foundation for Cardiovascular Research, Paavo Nurmi Foundation, Pirkanmaa Regional Fund of the Finnish Cultural Foundation, Competitive Research Funding of the Pirkanmaa Hospital District, Tampere Tuberculosis Foundation and the Sigrid Jusélius Foundation.

T. M. and A. M. T. are the present employees of Valio Limited, and S. L. and R. K. are the former employees of Valio Limited. Fermented milk products, which were delivered to the participants in all three study groups, were received 
from commercial source Valio Limited. Other authors have no conflicts of interest to declare.

The authors' contributions are as follows: M. K., T. M., A. M. T., H. V., R. K. and I. H. P. formulated the research questions; M. K., T. M., A. M. T., H. V., R. K. and I. H. P. designed the study; A. J. T., A. T., S. L., O. N. and I. H. P. carried out the study; E. J. H., A. J. T., K. N. and I. H. P. analysed the data; E. J. H., A. M. T., H. V. and I. H. P. wrote the article.

\section{References}

1. Beltran-Sanchez H, Harhay MO, Harhay MM, et al. (2013) Prevalence and trends of metabolic syndrome in the adult U.S. population, 1999-2010. J Am Coll Cardiol 62, 697-703.

2. Mancia G, De Backer G, Dominiczak A, et al. (2007) 2007 Guidelines for the management of arterial hypertension: The Task Force for the Management of Arterial Hypertension of the European Society of Hypertension (ESH) and of the European Society of Cardiology (ESC). Eur Heart $J$ 28, $1462-1536$.

3. Massey LK (2001) Dairy food consumption, blood pressure and stroke. J Nutr 131, 1875-1878.

4. Korhonen H (2009) Milk-derived bioactive peptides: from science to applications. J Funct Foods 1, 177-187.

5. Cicero AF, Gerocarni B, Laghi L, et al. (2011) Blood pressure lowering effect of lactotripeptides assumed as functional foods: a meta-analysis of current available clinical trials. J Hum Hypertens 25, 425-436.

6. Turpeinen AM, Jarvenpaa S, Kautiainen H, et al. (2013) Antihypertensive effects of bioactive tripeptides - a random effects meta-analysis. Ann Med 45, 51-56.

7. Xu JY, Qin LQ, Wang PY, et al. (2008) Effect of milk tripeptides on blood pressure: a meta-analysis of randomized controlled trials. Nutrition 24, 933-940.

8. Pripp AH (2008) Effect of peptides derived from food proteins on blood pressure: a meta-analysis of randomized controlled trials. Food Nutr Res 52, 10.3402/fnr.v52i0.1641 (epublication 18 January 2008).

9. Nakamura Y, Masuda O \& Takano T (1996) Decrease of tissue angiotensin I-converting enzyme activity upon feeding sour milk in spontaneously hypertensive rats. Biosci Biotechnol Biochem 60, 488-489.

10. Engberink MF, Schouten EG, Kok FJ, et al. (2008) Lactotripeptides show no effect on human blood pressure: results from a double-blind randomized controlled trial. Hypertension 51, 399-405.

11. van der Zander K, Bots ML, Bak AA, et al. (2008) Enzymatically hydrolyzed lactotripeptides do not lower blood pressure in mildly hypertensive subjects. Am J Clin Nutr 88, 1697-1702.

12. van Mierlo LA, Koning MM, van der Zander K, et al. (2009) Lactotripeptides do not lower ambulatory blood pressure in untreated whites: results from 2 controlled multicenter crossover studies. Am J Clin Nutr 89, 617-623.

13. Plat J \& Mensink RP (2005) Plant stanol and sterol esters in the control of blood cholesterol levels: mechanism and safety aspects. Am J Cardiol 96, 15D-22D.

14. AbuMweiss SS, Marinangeli CP, Frohlich J, et al. (2014) Implementing phytosterols into medical practice as a cholesterol-lowering strategy: overview of efficacy, effectiveness, and safety. Can J Cardiol 30, 1225-1232.

15. Turpeinen AM, Ikonen M, Kivimaki AS, et al. (2012) A spread containing bioactive milk peptides Ile-Pro-Pro and ValPro-Pro, and plant sterols has antihypertensive and cholesterol-lowering effects. Food Funct 3, 621-627.
16. Turpeinen AM, Kumpu M, Ronnback M, et al. (2009) Antihypertensive and cholesterol-lowering effects of a spread containing bioactive peptides IPP and VPP and plant sterols. I Funct Foods 1, 260-265.

17. Friedewald WT, Levy RI \& Fredrickson DS (1972) Estimation of the concentration of low-density lipoprotein cholesterol in plasma, without use of the preparative ultracentrifuge. Clin Chem 18, 499-502

18. Rule AD, Larson TS, Bergstralh EJ, et al. (2004) Using serum creatinine to estimate glomerular filtration rate: accuracy in good health and in chronic kidney disease. Ann Intern Med 141, 929-937.

19. Tahvanainen A, Koskela J, Tikkakoski A, et al. (2009) Analysis of cardiovascular responses to passive head-up tilt using continuous pulse wave analysis and impedance cardiography. Scand J Clin Lab Invest 69, 128-137.

20. Tikkakoski AJ, Tahvanainen AM, Leskinen MH, et al. (2013) Hemodynamic alterations in hypertensive patients at rest and during passive head-up tilt. J Hypertens 31, 906-915.

21. Koobi T, Kahonen M, Iivainen T, et al. (2003) Simultaneous non-invasive assessment of arterial stiffness and haemodynamics - a validation study. Clin Physiol Funct Imaging 23, 31-36.

22. Koobi T, Kaukinen S, Ahola T, et al. (1997) Non-invasive measurement of cardiac output: whole-body impedance cardiography in simultaneous comparison with thermodilution and direct oxygen Fick methods. Intensive Care Med 23, $1132-1137$.

23. Koobi T, Kaukinen S, Turjanmaa VM, et al. (1997) Wholebody impedance cardiography in the measurement of cardiac output. Crit Care Med 25, 779-785.

24. Dupont WD \& Plummer WD Jr (1990) Power and sample size calculations. A review and computer program. Control Clin Trials 11, 116-128.

25. Katz A, Nambi SS, Mather K, et al. (2000) Quantitative insulin sensitivity check index: a simple, accurate method for assessing insulin sensitivity in humans. J Clin Endocrinol Metab 85, 2402-2410

26. Lee CM, Huxley RR, Wildman RP, et al. (2008) Indices of abdominal obesity are better discriminators of cardiovascular risk factors than BMI: a meta-analysis. J Clin Epidemiol 61, 646-653

27. Lehtinen R, Jauhiainen T, Kankuri E, et al. (2010) Effects of milk casein-derived tripeptides Ile-Pro-Pro, Val-Pro-Pro, and Leu-Pro-Pro on enzymes processing vasoactive precursors in vitro. Arzneimittelforschung 60, 182-185.

28. Usinger L, Ibsen H, Linneberg A, et al. (2010) Human in vivo study of the rennin-angiotensin-aldosterone system and the sympathetic activity after 8 weeks daily intake of fermented milk. Clin Physiol Funct Imaging 30, 162-168.

29. Azizi M, Chatellier G, Guyene TT, et al. (1995) Additive effects of combined angiotensin-converting enzyme inhibition and angiotensin II antagonism on blood pressure and renin release in sodium-depleted normotensives. Circulation 92, 825-834.

30. Azizi M, Guyene TT, Chatellier G, et al. (1997) Additive effects of losartan and enalapril on blood pressure and plasma active renin. Hypertension 29, 634-640.

31. MacFadyen RJ, Elliott HL, Meredith PA, et al. (1993) Haemodynamic and hormonal responses to oral enalapril in salt depleted normotensive man. Br J Clin Pharmacol 35, 299-301.

32. Alderman MH, Piller LB, Ford CE, et al. (2012) Clinical significance of incident hypokalemia and hyperkalemia in treated hypertensive patients in the antihypertensive and lipid-lowering treatment to prevent heart attack trial. Hypertension 59, 926-933. 
33. de Denus S, Tardif JC, White M, et al. (2006) Quantification of the risk and predictors of hyperkalemia in patients with left ventricular dysfunction: a retrospective analysis of the Studies of Left Ventricular Dysfunction (SOLVD) trials. Am Heart J 152, 705-712.

34. Cicero AF, Rosticci M, Gerocarni B, et al. (2011) Lactotripeptides effect on office and 24-h ambulatory blood pressure, blood pressure stress response, pulse wave velocity and cardiac output in patients with high-normal blood pressure or first-degree hypertension: a randomized double-blind clinical trial. Hypertens Res 34, 1035-1040.

35. Jakala P, Pere E, Lehtinen R, et al. (2009) Cardiovascular activity of milk casein-derived tripeptides and plant sterols in spontaneously hypertensive rats. I Physiol Pharmacol 60, $11-20$

36. Ehlers PI, Kivimaki AS, Siltari A, et al. (2012) Plant sterols and casein-derived tripeptides attenuate blood pressure increase in spontaneously hypertensive rats. Nutr Res 32, 292-300.

37. Ogawa H, Yamamoto K, Kamisako T, et al. (2003) Phytosterol additives increase blood pressure and promote stroke onset in salt-loaded stroke-prone spontaneously hypertensive rats. Clin Exp Pharmacol Physiol 30, 919-924.

38. Turpeinen AM, Ehlers PI, Kivimaki AS, et al. (2011) Ile-ProPro and Val-Pro-Pro tripeptide-containing milk product has acute blood pressure lowering effects in mildly hypertensive subjects. Clin Exp Hypertens 33, 388-396.

39. Hendriks HF, Weststrate JA, van Vliet T, et al. (1999) Spreads enriched with three different levels of vegetable oil sterols and the degree of cholesterol lowering in normocholesterolaemic and mildly hypercholesterolaemic subjects. Eur J Clin Nutr 53, 319-327.

40. Baker WL, Baker EL \& Coleman CI (2009) The effect of plant sterols or stanols on lipid parameters in patients with type 2 diabetes: a meta-analysis. Diabetes Res Clin Pract 84, e33-e37.

41. Hernandez-Mijares A, Banuls C, Jover A, et al. (2011) Low intestinal cholesterol absorption is associated with a reduced efficacy of phytosterol esters as hypolipemic agents in patients with metabolic syndrome. Clin Nutr 30, 604-609.

42. Ooi EM, Watts GF, Barrett PH, et al. (2007) Dietary plant sterols supplementation does not alter lipoprotein kinetics in men with the metabolic syndrome. Asia Pac J Clin Nutr 16, 624-631.

43. Plat J, Brufau G, Dallinga-Thie GM, et al. (2009) A plant stanol yogurt drink alone or combined with a low-dose statin lowers serum triacylglycerol and non-HDL cholesterol in metabolic syndrome patients. J Nutr 139, 1143-1149.

44. Ockene IS, Chiriboga DE, Stanek EJ, et al. (2004) Seasonal variation in serum cholesterol levels: treatment implications and possible mechanisms. Arch Intern Med 164, 863-870.

45. Gould BA, Mann S, Davies AB, et al. (1981) Does placebo lower blood-pressure? Lancet ii, 1377-1381.

46. Appel LJ, Moore TJ, Obarzanek E, et al. (1997) A clinical trial of the effects of dietary patterns on blood pressure. DASH Collaborative Research Group. $N$ Engl J Med 336, $1117-1124$. 